\title{
THE DEVELOPMENT OF RESTRICTEDNESS IN THE SCIENCES
}

\author{
ARIE RIP \\ University of Leiden
}

\section{Introduction}

The technical side of science and its contribution to the dynamics of scientific developments are often neglected. As Derek de Solla Price complains:

It is unfortunate that so many historians of science and virtually all of the philosophers of science are born again theoreticians instead of bench scientists (1).

Theory is considered to be the distinguishing characteristic of science, and the source as well as the legitimation of the force of scientific knowledge. Again, some voices are raised against this received view:

Much of the potency of science must be related to the wide range of applicability of its standard procedures, and not to the possible deductions which can be made from its general laws. The role of deduction in science is grossly over-emphasized; natural applications of techniques are insistently perceived as logical or deductive moves (2).

In a more balanced view, theory as well as techniques should get their due, as in Bernal's aphorism: "Science, in one aspect, is ordered technique; in another, it is rationalized mythology" (3). The prevailing neglect of the technical side of science then becomes something to be explained, one of the reasons obviously being the higher status of mental labour compared with manual labour in our culture.

Philosophers of science, apart from their professional interest in theory and speculation, may be excused for their neglect of technical aspects because the discourse of science, especially in its publications, is much more accessible to outsiders than its empirical practices (4). The same excuse applies to sociologists of science, although with less force. Those philosophers of science who do give a lot of weight to the technical side, the actual control of nature, 
are often more interested in the consequences for the foundation of scientific knowledge (e.g., Janich, Mittelstrass (5)) or for ontological issues (e.g., Bhaskar (6)) than in elaborating a balanced view. Böhme and van den Daele, lately of the Max-Planck-Institute in Starnberg, are the exceptions, but their work has been discontinued for the moment (7).

For the sociologist of science, the important issues are how the technical side of science is involved in the dynamics of scientific developments, and what the impact of technical innovation and its diffusion is on scientific practices. These are large issues, and in this article I shall limit myself to a discussion of the concept of 'restrictedness' and how it may contribute to these issues.

The characterization of sciences as 'restricted' or 'unrestricted' has been introduced by Pantin (8) and elaborated by Whitley (9). Especially from Whitley's work, it is clear that 'restrictedness' is a bridging concept, combining features of the objects of the sciences and of their social organization. Neither Pantin, nor Whitley emphasize technical aspects in their discussion of 'restrictedness'. I shall argue that the restrictedness of a science depends on its control over the relevant part of reality, its ability to transform circumstances into parameters and variables. Such an interpretation of the concept of 'restrictedness' makes it possible to discuss technical dynamics in the sciences while including their social aspects. The approach of this article is thus the same as when Shinn argues that "the logic contained in experimental operations and the manipulation of instruments impinges significantly on the cast of social relations" $(10)$. The difference is that Shinn looks at the relation in contemporary laboratories, while I focus on its development over time.

\section{The Concept of 'Restrictedness'}

Whitley has shown how Pantin's rather unarticulated distinction between restricted and unrestricted sciences (for example, between physics and geology or parts of biology) can be made more precise and sociologically interesting by looking at science as productive labour (11). Scientific work is, as is work in general, concerned with transforming objects with tools for some goal. Differences between sciences will therefore at least to some extent be related to the specific features of what is being transformed and how, and such features will give rise to differences in work organization. 
For example, when unrestrictedness of a science is seen as the consequence of the "richness" of the constitutive phenomena, or of the complexity of the systems analyzed (as Pantin does, and Whitley sometimes), it seems plausible to associate it with field work and observation as the predominant styles of work. Restricted sciences, on the other hand, will rely on laboratory work. Geology or biology, and physics are paradigmatic examples of these relationships (12). Whitley elaborates this view further and considers also precision of work tasks (which will be high in restricted sciences and formally assignable), differentiation of work and enforcement of standards (again, high in restricted sciences) and nature of $\mathrm{PhD}$ training (routinized in restricted sciences).

Whitley's and Pantin's discussion of cognitive and social differences between physics and chemistry (considered to be highly restricted sciences) and biology and geology (partly or mostly unrestricted sciences) shows that there are clear differences. What is not shown, however, is that the root of these differences is a difference in knowledge object. The characterization of the nature and organization of work in restricted sciences, as given by Whitley and summarized above, may be seen as reflecting a high level of articulation and institutionalization, and not, or not immediately, a more restricted knowledge object. Given time and social support, unrestricted sciences may become institutionalized as well and show the same characteristics. The difficulty of distinguishing between the observed differences and their causes is compounded by the fact that differences between sciences, in style and organization of work, tend to diminish with the rise of professionalized science with a comprehensive "scientific method" (even if this is in fact the method of physics as perceived by outsiders).

One way of getting around the difficulty of analyzing differences between sciences in this way is to focus on the criterion of simplicity or complexity of the objects of the sciences. However, this approach faces methodological problems. The degree of complexity of the material object of a science is known only after the fact, when a consensus about its structure is reached. What has to be explained, however, is the relation between work style and organization of work, and features of the object at every stage of the historical practice of the science.

In Whitley's later presentation of the concept of restrictedness, there are still two aspects mixed up (13). He emphasizes ideals of explanation, e.g., 
the arithmomorphic ideal of working with objects constituted by simple elements that can be aggregated and dis-aggregated as one wishes. But a necessary component of restrictedness is also the ability to actually find or construct such elements in a satisfactory way. My point can be illustrated by quoting Ziman's discussion of physics as the art of the soluble:

It is not simply good fortune that physics proves amenable to mathematical interpretation; it follows from careful choice of subject matter, phenomena and circumstances (14).

Such choices are guided by explanatory ideals, e.g., of arithmomorphic explanation. But the success of the choices is based on actual transformation of his object:

In his experiments, the physicist contrives to create conditions that are simple to observe and analyse; ( . . .) He constructed artificial systems with nearly ideal properties; ( . . ) (e.g., purity, homogeneity) (15).

The success of such transformations will depend on the (unknown) nature of the material object, as well as on subcultural norms as to what constitutes success. Technical achievements are never just technical, there is always also a social component included.

Starting from the social aspects of scientific work, the decision whether a result is significant, or just noise or an artefact of the method, appears to be a matter of negotiation between actors, as has been shown by Collins in a number of cases (16). The goal of scientific work may be taken to be the reduction of ambiguity, and ambiguity of meaning is reduced by sociocognitive processes of argument, negotiation and institutionalization. An important input into this process is the reduction of ambiguity of outcomes with the help of technical means. (In a few cases, the outcomes are relatively unambiguous by themselves.) Although such inputs are still dependent for their significance on a negotiated consensus, they cannot be dissolved completely into social processes.

The arguments presented here show that there is room for special attention to the technical aspect of scientific work, and that it may be fruitful to take the ability to transform the object so as to have relatively unambiguous outcomes as the feature that distinguishes restricted from unrestricted sciences at any one moment in history. Restrictedness will then not be connected with the material or knowledge object of the science, but with the amount of 
control over the knowledge object. In restricted sciences, the behaviour of the knowledge object can be restricted, often very narrowly, to those aspects the researcher wants to study. In unrestricted sciences, this is not, or not very well possible, so that the behaviour of the object is unrestricted.

Since the definition proposed here is still directed toward the reduction of ambiguity, the implications for the nature of scientific work and its organization derived by Whitley on the basis of his definitions will still be applicable. In addition, increases in the degree of restrictedness of a science over time can now be linked directly to an increase in control over reality. This point will be developed in the next section.

In principle, all cases intermediate between a completely unrestricted science (if that may still be called a science) and a completely restricted science (if that still shows dynamic development) are possible. In contemporary science, however, unrestricted sciences are not free to choose whether to develop or not towards a higher degree of restrictedness. The high status of physics as the paradigm of a restricted science forces the practitioners of unrestricted sciences (e.g., the life sciences, but to some extent also the social sciences) to aim for more restrictedness, even if they have to import or imitate it. The alternative is to react against the status of physics as the ideal science and emphasize other approaches: holism in biology, configurations in sociology (17).

\section{The Production of Restrictedness}

Control over the knowledge object can be seen to increase through the successful production of pure samples (in chemistry and medicine), "pure" effects (in the physical sciences) and through tightly formulated procedures (18). The historical reconstruction of the dynamic leading to increased control is made difficult by the way modern science takes its power to control for granted. For instance, in chemistry pure compounds are considered to be non-problematic technically (they can be made) and conceptually (their definition is straightforward), while in fact, many chemists are not able to give an acceptable definition, and depend on commercial suppliers for their pure compounds (19). In this section, I shall use a few secondary sources to sketch an account of the development of pure samples and pure effects, without attempting a full reconstruction. 


\section{(a) The Production of Reproducible Samples}

The notion of a pure compound, or even of a sample with reproducible properties is absent in the lore and speculation of antiquity and medieval times. Chemical recipes for jewellers and colour-makers (for cosmetics and painting) became standardized to a certain extent, but did not guarantee reproducible results because the starting materials were not standardized as is still the case in cooking recipes (20). The craftsmen had to produce desired effects regularly, teach their pupils how to obtain these effects and assure themselves of a regular supply of reliable starting materials. Tests were used systematically only to detect frauds, especially in mint metal (21).

For the alchemists in antiquity, in the Arab world and in medieval Western Europe, purification of materials by fire was important, but only as a method or a therapeutical treatment to effect a transformation into gold. They did not bother to define their procedures and products, and the practical alchemical tradition was repeatedly turned into esoteric alchemy (22). Neither the alchemical theories of material change, nor the Aristotelian theory of generation and corruption provided incentives to develop the skills and procedures necessary to obtain pure samples.

Kuhn has emphasized the priority of a theory, as a promise of potential order, in the motivation of men to develop skills to convert potential into actual order, and has given an example of such a bootstrap operation in 19thcentury analytical chemistry (23). The development of chemical techniques from the 14th century through the 17th century, however, shows the theory (as commonly understood) is not necessary and other processes are at work (24). The search for quintessences and the technical innovation of distillation to produce more efficacious drugs was one of these processes, the other being the change in Moslem Spain from Galenic pharmacy, with its compounded vegetable drugs, to "simple" chemical remedies and the controversies in Western Europe over Paracelsian medical chemistry (including the attempts of the Paracelsians to remove the toxic properties of their medicines by reducing them to their essence) (25). The conception of purity as something to be separated from impurities evolved in this way, since people wanted to:

learne the manner to separate by Arte the pure and true substance as well manifest as hidden, the which in Phisicke is a great helpe to the taking away of diseases, harde or rebellious to be cured (26). 
The demand for drugs made it possible to gain a livelihood from the preparation of substances in the 16th and especially in the 17th century, while at the same time, a demand for chemical recipes and instruction grew (27). In the growth of analytical techniques (mineral waters and assaying being the most important), there is a continuity extending from the 16 th into the 19th century (28). Natural philosophy did play an independent role, especially in the introduction of corpuscular notions and the Cartesian explanation of the behaviour of acids and alkalis, but it was one component of a matrix in which medicine, alchemy and technology played their parts (29).

During the 18th century, especially in France, chemists who had been trained as pharmacists or physicians found a new and steadily expanding use for their skills in the solution of industrial problems (30). In Germany, Stahl and his followers formulated the phlogiston theory, partly in attempt to dissociate themselves from lowly pharmacists and disreputable goldmakers (31). The rationalization of chemistry by Lavoisier and his followers could build upon the results of these earlier developments. The notion of a pure sample was then related to the new theoretical structure, and this guided attempts to improve techniques and procedures.

The technical dynamic operated within a framework of theory, but after a time it became institutionally distinct from the ongoing research efforts in chemistry. When teaching laboratories were established in the course of the 19 th century, and later, when chemical analysis for monitoring purposes (e.g., water quality, industrial tests, food additives) became important around the turn of the century, the regular production of pure compounds became a necessary condition for obtaining reproducible results, and a commercially interesting proposition. At present, a number of big companies offer a large catalogue of chemical compounds and reagents ("chemicals"), graded according to purity. -

\section{(b) Changing Knowledge Objects}

This historical sketch of the production of pure samples can be interpreted as an account of a changing knowledge object. Slowly gathering momentum, the changes become more rapid from the 16th century onward. The end result is that the outcome of experiments depends less on the skill of the 
experimenter in handling diverse materials, than on preparing his materials to specification. Variability is restricted in this way and control over outcomes increased. A further step towards universal reproducibility was the institutionalization of procedures and tests and their incorporation in commercial production. Only at the research front do scientists still prepare their own samples.

The interpretation of the production of pure samples in terms of changing knowledge objects is supported by the occurrence of similar developments after the establishment of the concept of pure compounds and the techniques of preparation. When radioactivity was discovered by Becquerel in 1896 as mysterious "uranic rays", others tried to discover and isolate other radioactive substances by using the emitted radiation as the identifying indicator, the work of the Curies being the best known of these attempts (32). A lot of effort went into the study of the nature of the rays, but another line of research was initiated by Rutherford in 1899 through studying the changing radiation intensity of thorium oxide and discovering an "emanation" that itself showed some properties of radioactive substances. In this way, the study of radioactive degradation started, but it turned out to be very difficult to identify the substances produced. Experimental results were unsystematic because nobody knew the system behind it, it depended on the history of the sample, and different researchers produced mutually diverging results. Gradually, and mainly through Rutherford's efforts, standardized procedures to control the experimental set-up and identify substances by radiation patterns emerged. The resulting samples were identified by code names like Radium Emanation, Radium A, Radium B, Radium C, and, after further efforts, given a place in the periodic system of elements. The theory of radioactive transmutation, in the meantime, had to wait till the knowledge object had become manipulable at will; only then could it get down to systematic explanation.

This episode of confusion about radioactive substances was closed by 1913. A second example of changing knowledge objects is a still unfinished story. Thanks to techniques of isolation and fractionation, present-day biomedical research is able to produce all kinds of samples with biological effects. In a number of cases, standardized procedures are available to obtain samples with - hopefully - standardized effects, which are then adorned with code names like CRF, corticotropin releasing factor (33). In exceptional 
cases (which are then hailed as breakthroughs), chemically identifiable samples are produced, and the research then proceeds in terms of the chemical compounds. On many occasions chemical identification is not, or only tentatively, possible. Often, the identification methods that are used (e.g., immunological methods in the case of proteins) have their own, sometimes unexpected uncertainties (34). Latour and Woolgar provide fascinating inside views of scientific activity in these biomedical fields (35). In spite of the sophisticated instrumentation, the difficulties in standardizing and identifying samples are similar to 16th-18th-century chemistry and radiodegradation studies around the turn of our century. The sophistication, combined with the large scale of biomedical research, has made it possible for commercial firms to produce standardized samples ("biologicals"). It is an open question, however, if the knowledge object can be controlled sufficiently to initiate a theoretical dynamic typical of a restricted science.

\section{(c) The Production of Restricted Effects}

The aim of modern experimental science has been described as the production of effects:

The facts given in pre-scientific, everyday life become intersubjectively identifiable and reproducible: the phenomenon becomes an effect, the multiplicity of "influences" is differentiated and isolated (36).

In fact, as this quotation already suggests, for an effect to be scientifically relevant it should be a "pure" effect, unadulterated by "noise", in a definite situation and free from disturbances (37). One should, more neutrally, speak of restricted effects here; but purity (and order) are powerful concepts in our culture and their use dignifies even technical work.

Pure samples - that is, well-defined samples - are one way of increasing the probability of obtaining pure effects. Certain types of apparatus, for instance air pumps and Leiden jars, to name two that were popular in the 18 th century and important for the development of science, can be characterized as aimed at producing pure effects. If successful, they incorporate the control that has been won over some aspect of reality: they produce restrictedness where it was not present before.

According to Böhme and Van den Daele, instruments and apparatus (and 
also procedures) like air pumps and Leiden jars that produce or demonstrate certain effects are synthetic instruments, and should be distinguished from analytic instruments that extend and calibrate observation (38). They emphasize the role of both kinds of instruments in the development of science in the 17th and 18th century. Research into the way the instruments worked and attempts to refine and extend them provided the basis for theories of the phenomena produced or measured by them. Only after successful theory development (and the consequent rationalization of the instruments) is it possible to view instruments as embodied theory.

The first use of analytic instruments was to explore new domains (e.g., telescopes, microscopes); scales were used to indicate the occurrence of a loss or increase of weight, and only later in measuring the extent of the change. New instruments like barometers and thermometers were themselves objects of research, and gave rise to important scientific developments. Böhme and Van den Daele trace the design and performance norms regulating the technical-scientific dynamic, and show that universality, that is, independence of surroundings and of the materials used in the instrument, is more important than accuracy as such. Synthetic instruments also, and obviously, provide opportunities to study the effects they produce. This, as well as their possible entertaining and technological usages, determines the dynamic of their development.

From the 17th century until now, effects continue to be important: new domains are opened for exploration and their discoverers are honoured by eponymy. After a time, the production of the effect is brought under control and embodied in standardized apparatus (which sometimes takes off to a separate career in other sectors, for instance Röntgen apparatus in medical diagnosis and technological monitoring). The dynamic of the development at the research fronts, where new effects have to be domesticated, is still the same as in the 18 th century. But the instrument makers of that time, with their close relations to the evolving scientific community, have been replaced by a flourishing branch of industry. With the production of monitoring apparatus for applied science, industry and government as its origin and backbone, the scientific instrument industry has profited from the expanding market provided by modern scientific research, and now produces sophisticated instruments like NMR-spectrometers and special gaschromatographs. Industrial decisions and innovations influence scientific developments, as well 
as vice versa ; the present trend towards automation of analysis and measurement is a prime example (39).

\section{Some Implications of Increasing Restrictedness}

The increase in restrictedness in different sciences seems to be a rather general feature. Reasons could be several, from the ingenuity of homo faber and the scientific goal of universalism (requiring standardization) to the social and cultural goal of Western civilization to increase its control over nature and man. In any case, success in the sciences appears to be connected with restrictedness and increased control.

Within science, successful control is institutionalized through the reproduction of procedures and experimental set-ups, at first involving much skill and tacit knowledge (40), but after a time in a more standardized way and supported by regular training. The availability of ready-made restrictedness (in the form of instruments, directions for use and written instructions) allows further delegation of tasks. A division of labour results where technical assistants (and students) are responsible for the production of research outcomes. To ensure reliable results, a researcher now has to exert social control over his assistants, which replaces the direct technical control of the individual researcher of a previous age. Besides cognitive resources, now also social power becomes important, which is reflected in the internal struggles in the laboratory, as Shinn shows in his discussion of a solid state physics lab (41).

In the previous section, I have shown how the manufacture of pure samples and apparatus becomes independent of the scientific practices that gave rise to them. Wide use of such pre-packaged restrictedness implies then that scientific practices (in the same, but even more pronouncedly in other fields) will depend on the routinized supply of samples and apparatus. The effect of importation of restrictedness will depend on the nature of the object of the science and the existing organization of work. In many unrestricted sciences, instruments and standardized procedures are used primarily for gathering data, and do not have a great impact on its development (except building up "data pressure"). The imported restrictedness makes routinization of work possible, for instance, in the mineral chemistry laboratories studied by Shinn (42). 
There are obvious advantages in importing restrictedness. For an unrestricted science to really profit, however, it has to reorganize its practices. Organic chemistry during the decades before 1940 is an example of a semirestricted science with accepted, "chemical", criteria for proofs of molecular structures (43). After the Second World War, physical instruments were increasingly used to provide information about molecular structure and interaction, at first hesitantly and in the face of resistance from the old elite. Later on, it became commonplace, and the interpretation of the data provided was considered unproblematic, although chemical confirmation was still sought. At present, the use of sophisticated apparatus has become an indicator of respectable chemical work, and sometimes a criterion for the acceptance of articles (which cannot be met any more by the poorer laboratories).

The routinization of work and division of labour that is characteristic for restricted sciences according to Whitley, becomes possible in unrestricted sciences through importation of restrictedness,'as well as indigenous growth. The impact of routinization is felt at the lower strata of the scientific work force, including research students. The career perspective of most scientists, however, is to leave the drudgery of actually performing research tasks after a time. This makes them accept, and later forget their earlier experiences, and insufficiently aware of the influence of instrumentation and automation on selection and outcome of research problems (44). Quality control thus becomes difficult, but as an issue it normally remains part of scientific folklore. When restrictedness is imported, even the recognition of quality control problems recedes. Only when controversies erupt, as happens every now and then in food testing and environmental monitoring, will such issues become manifest (45).

Restrictedness in the sciences also has effects outside science. Human capacities to produce restricted situations outside the laboratory, transforming a local reality to be similar to the original experimental situation, are the essential precondition for applying science. A lot of effort, technical creativity and often social power is required to effect such a transformation.

The necessity of transforming reality to a restricted situation, before science can be applied, helps to explain the "external", often unexpectedly negative effects of the application of science. Agricultural science, for instance, although only partially restricted, needs monocultures to be applicable 
- as it were, the experimental plots enlarged $n$ times. The required intervention in the ecosystem has its repercussions, which can and should be distinguished from the side-effects of the applied science (for instance, with pesticides). Another example is that the scale and general infrastructure of power plants is often just as important as the specific technology (nuclear, oil- or coal-fired) being used - as is now slowly being realized in technology assessments (46).

\section{Concluding Remarks}

Viewing scientific developments as being partially determined by technical dynamics, and describing such developments in terms of restrictedness may also shed light on processes of theory formation. Increasing restrictedness leads to empirical generalizations and conceptual distinctions, i.e., "bottomup" theory formation (47). Other dynamics play a role, for instance, the speculative dynamic of world views like the mechanical philosophy of the 17 th and 18th century, or atomism until the 20th century. Such "top-down" theory formation may induce an explanatory dynamic or process of paradigm articulation, when the problems in the original explanation of the knowledge object of a research area are taken as the starting point for theoretical and experimental studies.

The existence of different dynamics in science emphasizes its heterogeneity, in spite of unified science ideals. In this respect, Kuhn's seminal article on the mathematical and experimental traditions in science is particularly interesting (48). According to Kuhn, the mathematical tradition, which goes back to antiquity and covers the "rational ordering sciences" (49), was transformed during the Scientific Revolution through the innovation of puzzle-solving groups, while at the same time a new tradition was born, the Baconian approach of "twisting the lion's tail", that is, subjecting nature to artificial experiments. The latter tradition carries the technical dynamic supporting increasing restrictedness, but ideals of rational ordering provide stimuli to the experimental tradition.

Kuhn emphasizes the separate evolution of the two traditions, sometimes far into the 19th century, because he is arguing against a unitary view of science (50). He also draws attention, however, to a reshuffling of the traditions from circa 1800 onwards, when (pure) mathematics split off, many 
Baconian sciences were mathematized, and mathematical physics took over the mathematical and mechanical tradition of the preceding centuries (51). In that period, the basis was laid for the combination of bottom-up and top-down theory formation, which in spite of its uncertain integration, is sometimes glorified as the scientific method (52).

Kuhn's analysis has limitations (53), but it does provide a historical basis for an analysis of the cognitive and social relations between disciplines, and, perhaps, a re-evaluation of the position of physics. One point is that, given the status of physics as the provider of the most basic explanations (54), theory formation in other sciences can proceed in two directions: further articulation according to its own explanatory dynamic, and connection with physical theory (by deduction, approximation, analogy or even more indirect means) (55). For instance, in organic chemistry bottom-up theory formation has been combined, first with the electron theories of the first decades of this century, and later with quantum theory.

By now, a separate specialty of quantum chemistry has evolved, which tries to specify the general equations of quantum mechanics to the level of molecular structure, developing specific approximations to reduce the complexity of chemically still rather simple molecules. Such an approach is an example of "top-down" theory formation: theoretical explanations are constructed speculatively in terms of axioms, general laws or approaches. Experiments may be designed to test and/or articulate such theories further. Especially if the status of the starting theory is high, however, the resulting theory may be used primarily as a ritual, as is the case in large parts of quantum chemistry (56). Practitioners in a science sometimes condemn the more baroque outgrowths of top-down theory elaboration. There are some cases, for instance, the quantum theory of the solid state in the 1930s, where an independent experimental dynamic comes to the rescue by providing opportunities for systematic articulation (57).

Another point is the question why the mathematical tradition, as carried on in contemporary mathematical physics, is more powerful than other traditions. Part of the answer lies in the extent of control over its knowledge object that physics has achieved and now exports to other disciplines. Other factors are the ideals of explanation that are favoured at some time (and which now may be slowly shifting in the direction of more holistic ideas, with 
a corresponding rise in the status of biology); and the social status of the practitioners of the different sciences.

Although data on social backgrounds and social status of practitioners of different disciplines are practically non-existent, some information about physicists and chemists provides a tantalizing glimpse of historical processes at work to keep a distance, both socially and intellectually, between the two disciplines. Kuhn notes that during the 17 th and 18 th centuries, practitioners in the mathematical tradition were more or less established, and held posts in universities and the newly-founded academies. Amateurs were the mainstay of the Baconian sciences, and even when practitioners of these sciences were members of an academy, they were most often second-class citizens (58). The role of different social groups and intellectual traditions in the origin and first phase of the Scientific Revolution is difficult to disentangle. In any case, the establishment of the royal academies in Britain and France may be seen as the first step towards pacification between the elite of the new science and social and political powers (59). Other such moves occurred at later stages; for instance, Stahl's efforts in Germany to put theoretical chemistry on the map (60).

When the mathematical and the experimental traditions become associated with different social statuses, this difference. will be maintained by social processes like co-optation, differential recruitment and social and intellectual distancing. Medically trained men for a time provided a middle ground, socially belonging to the higher classes, but intellectually often inclined toward the experimental tradition (or to holistic approaches as in the Naturphilosophie). After the complete mathematization of physics, the distinctions may become quite sharp, as shown for example by Pyenson and Skopp for physics and chemistry around 1900 (61).

Such thoughts are speculations, however. They have been set down because they derive from looking at science from the point of view of restrictedness, and combine social and cognitive aspects in a bridging concept. The fruitfulness of the concept of restrictedness itself lies in its bridging the gap between social and cognitive aspects of scientific developments, which is a necessary condition of achieving a real understanding of science. 


\section{Notes and References}

1. Derek de Solla Price, 'Philosophical Mechanism and Mechanical Philosophy: Some Notes Towards a Philosophy of Scientific Instruments', manuscript paper, Clark Library Seminar, UCLA, March 10, 1979.

2. Barry Barnes, Scientific Knowledge and Scientific Theory, London: Routledge and Kegan Paul, 1974, pp. 84-5.

3. J. D. Bernal, Science in History, Harmondsworth: Penguin, 1969, p. 3.

4. The bipartition of empirical approaches to the subject matter of science and the discourse about it is taken from Gernot Böhme, 'Cognitive Norms, Knowledge Interests and the Constitution of the Scientific Object: A Case Study in the Functioning of Rules for Experimentation', in Everett Mendelsohn, Peter Weingart and Richard Whitley (eds.), The Social Production of Scientific Knowledge, Dordrecht/ Boston: D. Reidel, 1977, pp. 129-41.

5. See for example Peter Janich, 'Physics - Natural Science or Technology?', in Wolfgang Krohn, Edwin T. Layton, Jr. and Peter Weingart (eds.), The Dynamics of Science and Technology, Dordrecht/Boston: D. Reidel, 1978, pp. 3-27; and Jürgen Mittelstrass, Die Möglichkeit von Wissenschaft, Frankfurt a/Main: Suhrkamp, 1974.

6. Roy Bhaskar, A Realist Theory of Science, Leeds: Leeds Books Ltd., 1975.

7. See, for instance, Gernot Böhme, Wolfgang van den Daele, 'Erfahrung als Programm - über Strukturen vorparadigmatischer Wissenschaft', in Gernot Böhme, Wolfgang van den Daele, Wolfgang Krohn, Experimentelle Philosophie, Ursprünge autonomer Wissenschaftsentwicklung, Frankfurt a/Main: Sukrkamp, 1977, pp. 183-236; and Gernot Böhme, Wolfgang van den Daele, and Wolfgang Krohn, 'The "Scientifica. tion" of Technology', in Krohn, Layton, Jr. and Weingart, op. cit., 1978 (Note 5), pp. 219-50.

8. C. F. A. Pantin, The Relations Between the Sciences, London: Cambridge University Press, 1968. Definitions are given on pp. 18 and 24 .

9. R. D. Whitley, 'The Sociology of Scientific Work and the History of Scientific Developments', in Stuart S. Blume (ed.), Perspectives in the Sociology of Science, Chichester: John Wiley, 1977, pp. 21-50. Some further refinements appear in Richard Whitley, "Changes in the Social and Intellectual Organization of the Sciences: Professionalization and the Arithmetic Ideal', in Mendelsohn, Weingart and Whitley, op. cit., 1977 (Note 4), pp. 143-69.

10. Terry Shinn, 'Scientific Disciplines and Organizational Specificity: The Social and Cognitive Configuration of Laboratory Activities', in this volume.

11. See Whitley, op. cit., Note 9, and for the general view Richard D. Whitley, "Components of Scientific Activities, Their Characteristics and Institutionalization in Specialties and Research Areas: A Framework for the Comparative Analysis of Zilian (eds.), Determinants in Karin D. Knorr, Hermann Strasser and Hans Georg Boston: Reidel, 1975, pp. 37-73. Controls of Scientific Development, Dordrecht/

12. Pantin, op. cit., 1968 (Note 8), seems to imply that there is a one-to-one relationship between restrictedness, artificial experiments and laboratory work on the one hand, and unrestrictedness, natural experiments (and observation) and field work on the other hand. His own designation of astronomy as a restricted science shows that other combinations are possible: astronomy of the planetary system relies on 
natural experiments. (It should be noted that astronomy is a difficult case to classify: as soon as it is concerned with origins and cosmology, disciplined speculation becomes important.) Examples of a combination of unrestrictedness and artificial experiments are provided by animal psychology and some parts of human psychology.

13. Whitley, 'Changes in the Social and Intellectual Organization of the Sciences', op. cit., 1977 (Note 9), p. 147. In the earlier article Whitley says "In some sciences, events and phenomena are embedded in a highly esoteric theoretical structure which requires elaborate technical facilities for their production. ( . . .) As I understand him, this view corresponds to objects in Pantin's 'restricted' sciences. In other fields, scientific objects are constructed in a less theoretically specific manner. They are not so narrowly conceived and incorporate a range of attributes and properties". Whitley, "The Sociology of Scientific Work and the History of Scientific Developments", op. cit., 1977 (Note 9), p. 26.

14. John Ziman, Reliable Knowledge. An Exploration of the Grounds for Belief in Science, London: Cambridge University Press, 1978, p. 28.

15. Ibid., pp. 29-30. Ziman does not elaborate this point because he is interested in epistemological issues. The moral he draws is: "Physics is the harvest of this Kantian fisherman (...)" (p. 30).

16. For example, H. M. Collins, 'The Seven Sexes: A Study in the Sociology of a Phenomenon, or the Replication of Experiments in Physics', Sociology 9 (1975) 205-24.

17. Compare Norbert Elias, 'Scientific Establishments', in this volume, also Whitley, 'Changes in the Social and Intellectual Organization of the Sciences', op. cit., 1977, Note 9.

18. Procedures in the sense of conceptual techniques, for instance Linnaeus' "artificial" classification of plants by selecting the reproductive organs as determinants of species and conceiving all other characteristics to be irrelevant; see Böhme and Van den Daele, op. cit., 1977 (Note 7), pp. 207-9.

19. See Barnes, op. cit., 1974 (Note 2), pp. 65-6 and P. Bulthaup, Zur gesellschaftlichen Funktion der Naturwissenschaften, Frankfurt a/Main: Suhrkamp, 1973, p. 70.

20. R. P. Multhauf, The Origins of Chemistry, London: Oldbourne, 1966, provides many examples for early chemistry. In some cases, the necessity of skillful handling can be traced until much later times, for example in the use of the blow pipe (Lötrohr) for analytical purposes (Ferenc Szabadváry, Geschichte der Analytische Chemie, Braunschweig: Friedr. Vieweg and Sohn, 1966, p. 70). Bulthaupt, op. cit., 1973 (Note 19), p. 71, quotes a textbook from 1913 saying that the uncertainties of situations calling for such skills contribute to the joy of discovery.

21. Multhauf, op. cit., 1966 (Note 20), p. 37; Szabadváry, op. cit., 1966, pp. 16-9. An assay of ore based on cupellation was specified in writing by royal decree in Hungary in 1342 (ibid., pp. 28-30).

22. Multhauf, op. cit., 1966, Note 20.

23. Thomas S: Kuhn, 'The Function of Measurement in Modern Physical Science', in The Essential Tension. Selected Studies in Scientific Tradition and Change, Chicago and London: University of Chicago Press, 1977, pp. 178-224. On p. 196 he discusses the work on multiple proportions that reached its final results only after Dalton's corresponding law was taken as a prior criterion. 
24. If Janich, op. cit., 1978 (Note 5), pp. 19-20, is followed, theory is considered as a means for making knowledge communicable, including the knowledge obtained by an experimenter in terms of what is and what is not successful. On such a view of theory, it does play an important role.

25. Multhauf, op. cit., 1966 (Note 20), pp. 216, 222, also 281; also Allen G. Debus, Man and Nature in the Renaissance, London: Cambridge University Press, 1978, pp. 29, 45-7, 53. There is a curious parallel in Debus's terminology for humanist methods, when he speaks about the humanist adherence to ancient philosophy "provided that they were assured that their texts were pure and unadulterated" (ibid., 7).

26. Debus, op. cit., 1978 (Note 25), p. 46.

27. Multhauf, op. cit., 1966 (Note 20), p. 353; also Marie Boas, The Scientific Renais. sance 1450-1630, London: Fontana Books, 1970, p. 154. Other developments are the wide circulation of recipe books and the start of industrialized drug production (Multhauf, op. cit., 1966 (Note 20), pp. 258, 262).

28. Szabadváry, op. cit, 1966 (Note 20), pp. 41-6 and 58-9.

29. Thus Multhauf, op. cit., 1966 (Note 20), p. 349.

30. Henry Guerlac, 'Some French Antecedents of the Chemical Revolution', Ambix 5 (1959) 73-112.

31. Karl Hufbauer, 'Social Support for Chemistry in Germany during the 18th Century: How and Why Did It Change?' Historical Studies Phys. Science 3 (1971) 205-31. The strategy of intellectual distancing noted here is treated also by R. G. A. Dolby, 'On the Autonomy of Pure Science: The Construction and Maintenance of Barriers between Scientific Establishments and Popular Culture', in this volume.

32. The discussion in this paragraph is based on Alfred Romer (ed.), Radiochemistry and the Discovery of Isotopes. New York: Dover, 1970. See also T. J. Trenn, The Self-Splitting Atom. A History of the Rutherford-Soddy Collaboration, London: Taylor and Francis, 1977.

33. Nicholas Wade, 'Guillemin and Schally: The Years in the Wilderness', Science 200 (1978) 279-82; also Bruno Latour and Steve Woolgar, Laboratory Life. The Social Construction of Scientific Facts, Beverly Hills and London: Sage, 1979, p. 60.

34. Lois Wingerson, 'Mistaken Identity of Proteins Threatens Biochemists' Results', New Scientist 86 (24 April 1980) 192-3.

35. Latour and Woolgar, op. cit., 1979, Note 33.

36. Böhme and Van den Daele, op. cit., 1977 (Note 7), p. 223 (my translation).

37. The experimenter in fact attempts to control chaos (compare Ziman, op. cit., 1978 (Note 14), p. 59) and in spite of the successful exclusion of ever more "disturbing factors", ambiguity remains: is the effect real, or a result of a "dirty system"?

38. Böhme and Van đen Daele, op. cit., 1977, Note 7. The same distinction is made by Janich, op. cit., 1978, Note 5 .

39. Studies of the development of the instrument industry have mostly concentrated on the economic aspects. The inter-relationships with scientific developments and the problem of quality control are well worth further study. In chemistry, for instance, the classical elemental mass analysis is now fully automated, and often performed by special laboratories. Folklore has it that one in ten analyses goes wrong, and that mistakes are not always spotted. Clinical analyses are troubled by the same problem, aggravated by the greater variability of the samples and the risk 
of human suffering caused by errors. Indicative is a conclusion of Ferreira and Bold, when they state: "An accurate analysis is not as simple as is implied in advertisements. Reliable results can only be obtained by a skilled operator who has a thorough knowledge of the possible pitfalls involved" (P. Ferreira and A. M. Bold, 'Clinical Laboratory Evaluation of the Orion SS-20 Ionized Calcium Analyser', J. Automatic Chem. 1 (1979) 94-102, p. 101).

40. See, for example, H. M. Collins, 'The TEA Set: Tacit Knowledge and Scientific Networks', Science Studies 4 (1974) 165-86.

41. Shinn, op. cit., Note 10.

42. Ibid.

43. Organic chemistry was a restricted science in the sense that it could dispose of well-defined samples and standardized techniques to prepare them. It was unrestricted in the sense that properties and reactions of the samples and compounds could not be controlled, in spite of a huge amount of accumulated experience and some empirical generalizations. (See also Emil Broesterhuizen, Arie Rip, Organic Chemistry, A Techno-Science. Speculations about Theory Development in Organic Chemistry, unpubl. report (nr. 7801), Leiden: Chemistry and Society Programme, 1978).

44. This view was suggested to the author by P. Groenewegen.

45. A number of historical and contemporary examples are analyzed by Ross Hume Hall, Food for Nought, The Decline in Nutrition, Hagerstown (Mld.): Medical Dept., Harper \& Row, 1974. In environmental controversies about levels of lead, DDT and PCBs, the suspicion that concern is caused by increased sensitivity of the instruments is often voiced by industry.

46. A (dramatic) example of some repercussions of application, undercutting the universal validity of the original scientific findings, is the case of DDT: it killed mosquitoes in the $1950 \mathrm{~s}$, but fails to do so in the $1970 \mathrm{~s}$ - at least, in some parts of the world. G. Böhme, Wolfgang van den Daele, Wolfgang Krohn in 'Finalization in Science', Soc. Sci. Information 15 (1976) 307-30, p. 323, comment as follows: "The perspective of nature as an infinite reservoir for intervention cannot be abandoned as long as the theories of natural science do not make it possible to integrate the historical impact of such intervention into their concepts. Therefore, scientific knowledge will continue to refer to reproducible possibilities, even if the presuppositions of these possibilities are undermined precisely by the process of their reproduction." They continue to plead for ecology as a normative, strategic science.

47. Böhme and Van den Daele, op. cit., 1977 (Note 7), p. 214. One of their examples that supports my point about restrictedness giving rise to bottom-up theory formation is experimental electricity in the 18th century (p. 195). This appears to be also the conclusion of J. L. Heilbron, Electricity in the 17th and 18th Centuries. A Study of Early Modern Physics, Los Angeles and London: University of California Press, 1979.

48. Kuhn, op. cit., 1977, (Note 23), pp. 31-65.

49. Böhme and Van den Daele, op, cit., 1977 (Note 7), p. 206.

50. Kuhn, op. cit., 1977 (Note 23), pp. 31-3, 46.

51. Ibid., pp. 60-5. Compare also the quotation from Heilbron, Note 47.

52. This discussion does not do justice to the complexity of the social, cultural and 
technical transformations of this period, of which the transformation of science is "nut one part. An important aspect of this transformation is, for instance, how compare David Knight, The Nature of Science. The Histor mechanical tradition; Culture Since 1600, London: Andre Science. The History of Science in Western der Naturgeschichte, München, Wien: Carl Haner 1976, and Wolf Lepenies, Das Ende

53. Kuhn, op. cit, 1977, Note 23, notes his manser Verlag, 1976.

sciences (footnote 9, p. 40-41), and makes a passing life sciences and medical being important for scientific development, but available remark about elaborate data fulfills some perceived social function (footnote $6, p .38$ )

54. See Arie Rip 'Science Policy and (footnote 6, p. 38).

baut, M. de Mey, R. Pinxten, F. Vandamme Picture of the World', in W. CalleScience Policy, Ghent: Communication and Cognition, Theory of Knowledge and

55. There is an interesting analogy with the way "rion, 1979, pp. 358-77.

rules important in technology and industry, are af the thumb", the empirical in an empirical way, or an attempt is made to re articulated: they can be refined knowledge. The connection between more empirical them to the body of scientific edge and general, fundamental theory is in both or application oriented knowlfrom the one predicted by the finalization thesis cases in the opposite direction op, cit., 1976, Note 46).

56. Broesterhuizen and Rip, op. cit., 1978, Note 43.

57. E. Homburg, personal communication, based on the case-study of solid state physics and solid state phy sicists in.Loet Leydesdorff e.a.,Philips en de wetenschap,
Amsterdam: SUA, 1980 .

58. Kuhn, op. cit, 1977 (Note 23), pp. 51-2, also Multhauf, op. cit., 1966 (Note 20), p. 269, and Debus, op. cit., 1978 (Note 25), p. 140.

59. The English case has been studied by Wolfgang van den Daele, 'The Social Construction of Science: Institutionalization and Definition of Positive Science in the Latter Half of the 17th Century', in Mendelsohn, Weingart and Whitley, op. cit., 1977
(Note 4), pp. 27-54.

60. See Hufbauer, op. cit., 1971, Note 31.

61. Lewis Pyenson and Douglas Skopp, "Educating Physicists in Germany circa 1900", Social Stud. Sci. 7 (1977) 329-66. They note that chemical training is an avenue of social mobility, while physics is closely connected with the elite. 